\title{
Plagiorism: Threat to Intellectual Right in Biomedical Journalism
}

\author{
Dr Manish Bajracharya
}

\begin{abstract}
Plagiarism has become a serious threat concerning to intellectual right especially in medical/dental journalism in recent years. It is a matter of fact that, all medical practitioners cannot be academicians, all academicians cannot be researchers, and all researchers cannot be the writers. Scientific medical writing is in fact is an amalgamation of medical science, academia, research and authorship. There is a huge pressure on medical doctors especially faculty members for the publication of scientific article for the purpose of promotion or selection. Many institutes have made it mandatory to medical students for publication during the residency program. Due to the intense competition amongst the peers and for the existence of oneself; the fake publication may evolve in the notion of "publish or perish". Eventually many predatory authors opt to commit plagiarism deliberately or unintentionally as an easy path to success or due to their incompetence regarding the scientific writing.
\end{abstract}

Plagiarism is a form of academic dishonesty. The word is derived from Latin word 'plagiarius'; which means 'kidnapper'. According to Merriam-Webster dictionary; the term plagiarism means to steal and pass off the ideas and words of other as one's own, to use other's production without crediting the source, to commit literary theft, or to present as new and original idea or product derived from an existing source.

Plagiarism has been explained into five types; viz. copy and paste, word switch, metaphor, style plagiarism and idea plagiarism.' Thus the statements and ideas which is not one's own should be cited to original source. Although there is no any clear rule as to how much copying is plagiarism; less than $20 \%$ is often ignored by major international journals. ${ }^{2}$ Nevertheless, it should be kept in mind that, seemingly simple act like 'switching the words' does not exclude oneself from the fraudulence. No matter how the academic misconduct is committed; the person cannot be exempted from the consequences of committing an offensive crime. The results may be article retraction, banning for publication, suspending the professorship for a period of time, or even losing the degree.

Feng et $\left.a\right|^{3}$ reported that a total of 2047 biomedical and life-science research articles indexed in PUBMED were retracted as of May 2012; in which more than $67 \%$ were due to academic misconduct that included data fabrication, data falsification, duplicate publication and plagiarism. Interestingly; USA, Germany, Japan and China were responsible for three quarters of the retraction due to fraud or suspected fraud. On the other hand, China and India were more responsible for plagiarism. There is a site: 'www.retractionwatch.com' which comprises of the list of retracted articles with the details on retraction.

Original ideas are considered to be an intellectual property and in most of the countries it is protected by the copyright law. However, in our subcontinent the laws are not strict and the biomedical publications are not confounded to a single country's boundary. Unfortunately, one can access to any article online and commit the plagiarism act; thinking that they can get away with the unethical act; but that will haunt them in the long run if not immediately.

So what can be done in order to avoid academic misconduct? The academic institute should provide a platform to educate the students about the ethical publication. The INASP; an international charity agency working in various developing countries including Nepal for sharing of research and knowledge, has been actively conducting many programs in collaboration with Tribhuvan University, Kathmandu University, Nepal Association of Medical Editors (NAME) for ethical publications. Participating in such seminars will help to understand about avoiding academic misconduct. Actually, not only the students, faculty members should also be honest with their research work; after all they are the ones who truly guide the students.

Rogers ${ }^{4}$ recommended on how to avoid plagiarism; they are (1) use quotation marks around words taken verbalism from a source, (2) do not change any part of quotation in the context of a sentence, (3) use single quotation marks for a quotation within a quotation, (4) use ellipsis (3 periods with a space before, between and after them) for a part of a quotation omitted, (5) use brackets around words added to the quotation, (6) limit the use of direct quotes, and (7) attempt to paraphrase or summarize the information from a variety of sources in one's own words.

The site like www.plagiarism.org provides the detail on plagiarism and how to avoid it. Orthodontic Journal of Nepal (OJN) used software 'Plagiarism' in the past and is currently using the software 'ithenticate' for detecting plagiarism which we hope has been a boon for improving the quality of the journal.

\section{REFERENCES}

1. Five types of plagiarism. Available at: http://www.lib.ncsu.edu/lobo/lessonplans/14fivetypes.doc. Accessed 1/20/2013.

2. Krishnan V. Etiquette in scientific publishing. Am J Orthod Dentofacial Orthop. 2013;144:577-82

3. Feng F, Steen R, Casadevall A. Misconduct accounts for the majority of retracted scientific publications. Proc Nat Acad Sci USA. 2012; 109:17028-33.

4. Rogers B. Using the words and works of others: A commentary. AAOHNJ. 1993; 41:46-9. 